\title{
Gestão escolar e novos desafios no currículo: projetos educomunicativos no ensino médio
}

School management and new challenges in the curriculum: educommunication

projects in high school

\author{
Wellington Luiz Salgado ${ }^{1}$, Rosebelly Nunes Marques², Flávia Pierrotti de Castro ${ }^{3 *}$
}

${ }^{1}$ Graduado em História - Universidade de Taubaté (UNITAU) - Rua Quatro de Março, 432 - Centro, 12020-270, Taubaté, SP - Brasil

${ }^{2}$ Universidade de São Paulo - Docente do Departamento de Economia, Administração e Sociologia LES/ESALQ - Av. Pádua Dias, 11, 13418-900, Piracicaba, SP - Brasil

3*Universidade Federal de São Carlos - UFSCar - Doutoranda do Programa de Pós-Graduação em Química - Rodovia Washington Luís, km 235 - $13565-905$ - São Carlos, SP -

Brasil<flavia_pierrotti@yahoo.com.br>

\section{Resumo}

Este artigo discute os aspectos pedagógicos relevantes e as dificuldades da gestão escolar na formulação, implantação e condução de Projetos Educomunicativos que envolvam o uso de tecnologias da informação e da comunicação no Ensino Médio. A metodologia para pesquisa foi a pesquisa-ação. Os desdobramentos da pesquisa foram baseados nos relatos e observações de experiências em dois colégios privados situados no Vale do Paraíba, SP. No primeiro projeto, o pesquisador atua como professor/mediador da rádio escolar. No segundo projeto, atua como gestor escolar do ensino médio e participa como observador e colaborador do projeto escolar de produções midiáticas, introduzido e coordenado por uma mediadora especialista em Educação e Comunicação. Os projetos foram desenvolvidos entre 2014 a 2017. Os resultados da pesquisa propõem a reflexão do objetivo das ações pedagógicas que envolvem meios tecnológicos no espaço educativo, pois nos processos de aprendizagem pode ocorrer o desvirtuamento dos objetivos pedagógicos iniciais dos projetos. Nos casos observados nesta pesquisa, eles acabaram atendendo à meta lucrativa da instituição no ensino privado deixando de lado a importância pedagógica proposta para o desenvolvimento do discente.

Palavras-chave: cultura escolar, educomunicação, pesquisa-ação, tecnologia

\begin{abstract}
This paper discusses the relevant pedagogical aspects and the difficulties of school management in the formulation, implementation and conduction of Educommunication Projects that involve the use of information and communication technologies in the high school. The methodology for research was action research. The results of the research were based on the reports and observations of experiences in two private schools located in Vale do Paraíba-SP. In the first project, the researcher acts as teacher / mediator of the school radio. In the second project, he acts as a high school manager and participates as an observer and collaborator of the school project of media productions, introduced and coordinated by a mediator specialized in Education and Communication. The projects were developed between 2014 and 2017. The results of the research propose the reflection of the objective of the pedagogical actions that involve technological means in the educational space, because in the learning processes, the initial pedagogical objectives of the projects can be distorted. In the cases observed in this research, they ended up meeting the lucrative goal of the institution in private education leaving aside the pedagogical importance proposed for the development of the student.
\end{abstract}

Keywords: school culture, educommunication, research-action, technology

\section{Introdução}

Refletir acerca dos desafios da implantação, por gestores, de Projetos Pedagógicos Educomunicativos, que consiste em planejar e pôr em prática ações que tem que objetivo criar e desenvolver interações entre as pessoas presentes no espaço escolar, possibilitando a expressão de todos os integrantes dessa comunidade (Soares, 2011), envolvendo o uso de tecnologias da informação e comunicação, para o desenvolvimento dos currículos anuais do Ensino Médio, é essencial. A atualidade e a cultura da mídia que nos envolve requer atenção especial para as intersecções entre os campos da Comunicação e da Educação. McLuham (2002), na década de sessenta, chamava a atenção para o deslumbre que as tecnologias exercem e para a essencialidade das discussões sobre isso, é a extrema utilização da tecnologia que criam, que transformam seres antropocentristas, nos deleitando e se maravilhando com nossa própria imagem.

Pensando na proximidade com a tecnologia, é importante ressaltar que o uso dos dispositivos no ambiente escolar seja realizado mediante o cumprimento de seus objetivos pedagógicos, das intenções e otimização dos processos educativos, proporcionando mudanças (Toschi, 2005).

Recebido: 23 out. 2017

Aprovado: 26 abr. 2018 
Desse modo, projetos educomunicativos podem se configurar como uma nova vertente possível para atingir o indivíduo com estratégias e linguagens contemporâneas transformando assim a sociedade e mentalidades das novas gerações, inovando, na prática, o processo metodológico de ensino da equipe docente.

As práticas educomunicativas propõem novas possibilidades de linguagens e códigos na sala de aula e no ensino. Como afirmou Moran (2000), a escola deve conhecer e significar essas novas formas de comunicação, codificando-as e assim controlar as diversas formas de manifestação e seus possíveis direcionamentos para aproximar o discente, os novos docentes e o sistema educacional da nova realidade do aluno e dos seus anseios de aprendizagem.

As instituições de ensino precisam, portanto, investir na modernização estrutural e formação acadêmica para concorrer de forma leal com o mundo fora dos muros escolares, pois, de acordo com Alcici (2014) é difícil para as escolas compreender que os alunos não são mais os mesmos, que estes estão submersos no mundo tecnológico, e o ambiente escolar precisa evoluir na questão tecnológica para formar a nova juventude.

Logo, o embasamento teórico proposto por esse artigo segue os caminhos desenvolvidos pela nova área do conhecimento conceituada como educomunicação, que busca um diálogo entre a comunicação e a educação, as metodologias pedagógicas e suas estratégias que propõem o ensino por projetos educacionais e das bases teóricas que propõem o uso das tecnologias da informação e da comunicação [TICs] no ensino. Conforme Soares (2011), a Educomunicação é a conduta em sociedade, formando um modelo de que direciona o gerenciamento das decisões que ocorrem no âmbito social. Ela não envolve, portanto, o simples uso das TICs no ensino, mas sim um desenvolvimento de novos métodos na formação educacional, colocando assim o jovem discente como protagonista neste enredo, participando das ações diversificadas (gestão da comunicação, da expressão estética, utilização das tecnologias nos espaços escolares, ensino da receptividade) sempre interagindo com uma intenção de comunicação (Soares, 2011).

Essa é uma nova área de intervenção social que se configura como importante para pensar a formação do Ensino Médio de maneira diferenciada da atualidade. $\mathrm{Na}$ verdade, pensando na renovação das práticas sociais que desenvolva cada vez mais a formação humana, principalmente da infância e da juventude.

Neste contexto, o objetivo deste artigo foi refletir sobre os aspectos pedagógicos relevantes e as dificuldades envolvidas na formulação, implantação e condução de Projetos Pedagógicos Educomunicativos vivenciados no Ensino Médio de duas instituições privadas em duas cidades distintas do Vale do Paraíba - SP. A partir do objetivo proposto, compreende-se que as reflexões devem extrapolar o campo pedagógico, e abarcar algumas reflexões também no campo mercadológico, pois projetos com esta vertente proporciona outros olhares por parte das instituições de ensino. Dessa forma, a discussão proposta permitirá a percepção de duas vertentes para analisar, o pedagógico e o mercadológico.

\section{Material e Métodos}

A pesquisa foi iniciada com uma revisão bibliográfica para embasamento teórico e conhecimento de relatos de projetos e instituições de ensino que trabalharam em seu currículo anual com a pedagogia de projetos. Segundo Gil (2010), a pesquisa bibliográfica se baseia em inúmeras publicações, que podem ser elencadas por revistas, teses, artigos científicos, sítios eletrônicos e livros. Logo, buscou-se a leitura e o aprimoramento da revisão bibliográfica proposta. Porém, a observação e as anotações das experiências no ambiente escolar foram fundamentais para os resultados propostos por esta pesquisa. A pesquisa empírica possibilita ter uma real noção, na prática, dos estudos teóricos.

Os Projetos Pedagógicos Educomunicativos que são objetos de estudo nesta pesquisa ocorreram em duas instituições particulares, de cidades do interior de São Paulo, localizados no Vale do Paraíba. A distância entre o colégio Alfa e Beta são de aproximadamente $47 \mathrm{~km}$, pois as escolas situam-se em cidades próximas.

O primeiro projeto aconteceu no período de 2014 a 2016 no colégio que foi denominado de forma fictícia como Alfa, que oferece ensino médio e técnico. O segundo projeto ocorreu no colégio,denominado de forma fictícia como Beta. Essa escola atende alunos do ensino infantil, fundamental, médio e técnico.

Nos dois colégios, foi realizada uma pesquisa-ação com bases conceituadas nos processos educomunicativos, como a rádio e produções audiovisuais. Moreira e Caleffe (2008) definiram pesquisa-ação como uma sucinta perturbação do equilíbrio da realidade e uma análise próxima dos efeitos dessa perturbação. Esse tipo de pesquisa é situacional, ou seja, parte-se de um problema em um contexto específico e busca-se sua solução; é também colaborativa e participativa, isto é, o pesquisador é o responsável ou orienta a pesquisa junto com outros participantes. Além disso, é autoavaliativa, pois existe uma preocupação em mensuraras ações continuamente a fim de fazer constantes correções (Moreira e Calefe, 2008).

A pesquisa-ação além do caráter deliberado de intervir e transformar os resultados finais da pesquisa, também possibilita uma transformação emancipatória no sujeito e no grupo que sofre tais influencias, conscientizando a todos que participam dos projetos. 
De acordo com Franco (2005) o discurso de todos os envolvidos será integrado no desenvolvimento da investigação. O método não será definido por etapas, e sim, a partir das situações que se apresentam ao longo do processo, dando o foco formativo dessa metodologia, em que o sujeito observa as alterações de si e do processo de investigação.

Seu caráter formativo no processo do sujeito possibilita uma ação mais democrática tanto no decorrer do projeto educacional, como também nos trilhos seguidos pela pesquisa teórica. Para justificar o uso desta metodologia e suas ações, observa-se o caráter pedagógico e educacional do projeto, em que envolve uma ideologia formativa do sujeito.

Conforme ainda sugere Franco (2005) a pesquisaação é acima de tudo uma pesquisa pedagógica, que leva em consideração o exercício do fazer pedagógico e também traz o caráter científico para a prática educativa. Neste contexto, a pesquisa embasou-se no campo educacional com profundo respeito aos princípios ideológicos da emancipação e da formação do sujeito partindo do problema, com transformações nas práxis e ações sociais.

No colégio Alfa, o pesquisador, na época professor da escola, foi responsável pela organização e administração dos trabalhos. No colégio Beta, o pesquisador não atuou diretamente na execução do projeto. Nesse caso, partiuse do olhar do gestor escolar do Ensino Médio, com a missão de aprovar e contribuir na implementação e condução da ação escolar com propostas educacional e comunicativa por uma educadora com especialização em Educação e Comunicação. As observações e registros ocorreram no período do segundo semestre de 2015, no ano de 2016 e no primeiro semestre de 2017.

\section{Colégio Alfa: Projeto Rádio Alfa}

A Rádio Alfa teve seu início no ano de 2014, coordenado por este pesquisador, fundador do projeto, que atuava na instituição como professor de História no Ensino Médio. A participação deste professor foi até o final do ano de 2016. O primeiro passo foi a seleção de alunos totalizando doze membros, todos com funções pré-estabelecidas. O processo de seleção foi por intermédio de redação produzida pelos alunos com o seguinte tema: "Por que eu seria perfeito (a) para participar da Rádio do meu colégio? ". Teve noventa e duas redações e selecionou-se 20 para a segunda fase, a entrevista com uma banca de três professores. Após o processo de entrevista, doze alunos ocuparam as vagas.

$\mathrm{O}$ segundo passo seguindo o processo para o desenvolvimento do projeto foi trabalhar com os alunos em Oficinas de Comunicação, um período de cinco encontros durante todas as quintas-feiras com $2 \mathrm{~h} 30 \mathrm{~min}$ de duração, com a meta de desenvolver conhecimentos básicos acerca da Comunicação e os meios técnicos. Foram discutidos temas como ética e respeito nas vias de comunicação; conhecimento sobre software para programação, edição e transmissão; funcionamento da rádio por meio de cronogramas; funções dos profissionais como locutores, âncora, editores, repórteres, técnico de som, assessoria de imprensa e outras funções, como o coordenador e o curinga (aluno que tem domínio de todos os processos).

Depois das oficinas, iniciou-se o processo de criação e gravações de vinhetas, que incluíam momento pedagógico, curiosidades, esportes, cultura e reflexões. Tudo era gravado nos encontros que aconteciam todas às quintas-feiras no período da tarde, das $13 \mathrm{~h} 30 \mathrm{~min}$ às $16 \mathrm{~h} 00 \mathrm{~min}$. As gravações precisavam ter uma duração diária de no máximo dezenove minutos no intervalo do colégio. Como percebeu-se que era muito tempo, foram feitos ajustes inserindo músicas durante a programação preparada pelos alunos e professor.

Logo, a programação da rádio semanal ficou estabelecida da seguinte forma: às segundas, quartas e sextas-feiras havia os avisos, o momento pedagógico, as músicas e momento de esportes; às terças-feiras havia o momento curiosidade, o boletim semanal e músicas; às quintas-feiras ocorria apresentação de entrevistas com os professores e funcionários, debate, momento reflexão adolescente e músicas. Era possível realizar toda a edição da produção da programação semanal por meio das captações anteriores para os encontros de quinta-feira. Toda a edição era feita por intermédio do programa de software "Audacity".

\section{Colégio Beta: Projeto Videobeta}

O Projeto Videobeta foi implantado no colégio pela professora da disciplina de História da Arte. Esta professora tem Especialização em Educação e Comunicação. Esse projeto tinha por objetivo produções de audiovisuais - vídeos de dois a cinco minutos - de acordo com o desejo dos alunos de expor suas ideias. O projeto era norteado pela produção midiática como um meio de envolver o aluno e novos conhecimentos tecnológicos e comunicativos, tendo como o elemento principal o olhar do aluno e sua opinião, ou seja, evidenciar o protagonismo jovem.

Iniciou-se o projeto em 2015, só com um processo de seleção de inscrição dos interessados, seguido de entrevistas. Foram selecionados dez alunos do $8^{\circ}$ ano do Ensino Fundamental II ao $3^{\circ}$ ano do Ensino Médio. Após a escolha dos membros do grupo, iniciou-se o processo de "alfabetização midiática", ou seja, de aprendizagem de

${ }^{1}$ Software para edição de áudio, simples e com vários recursos de fácil manipulação para utilização com os discentes em projetos escolares. Disponível gratuitamente em: <http://www.audacityteam.org/download/>. 
como fazer captação de imagens, edições em software, administração de redes sociais e busca de matérias para alimentar o Projeto.

Os encontros dos grupos ocorriam todas às sextasfeiras, das 14h00min às 16h30min, na sala da coordenação para o uso do computador e captação de som, pois foi o lugar que os alunos julgaram ter ótima acústica para captação do som nas entrevistas. A programação consistia em buscar assuntos e entrevistados, após essa fase captava imagem e som, e na fase seguinte, ocorria o processo de edição para postagens nas redes sociais. Dessa forma, não existia um cronograma certo a ser seguido, como no projeto da rádio, pois seguia o interesse dos alunos pelo assunto a ser abordado.

Às vezes, os estudantes queriam falar de assuntos relacionados à adolescência, como sexo e drogas; outras vezes queriam gravar vídeos da aula "legal" ou interessante de determinado professor e discutir o conteúdo abordado na aula captada. Então, todo esse processo para as produções audiovisuais ocorreu durante três meses para cada vídeo produzido: duas produções no ano de 2015 e três produções durante o ano de 2016.

Esse tempo todo para cada vídeo produzido ocorre em virtude de vários fatores do processo de produção: levantar o assunto a ser abordado; realizar um roteiro para produção; desenvolver as perguntas para serem feitas na entrevista; selecionar os entrevistados e marcar com eles a captação de imagens; editar e aprovar produção final; e, por último, divulgar e postar nas redes sociais, site institucional e posteriormente em outra rede social de compartilhamento de vídeos e fotos. Por isso, o processo necessita de uma demanda maior de tempo para a sua execução.

\section{Resultados e Discussão}

O objetivo de projetos que envolveram as tecnologias da informação e da comunicação no favorecimento da educação foi, essencialmente, procurar desenvolver o protagonismo do jovem aluno. Isso envolveu a atuação do discente no processo educacional, isto é, a oportunidade de ele demonstrar sua visão e sua produção para o público escolar. Assim, encontra-se um espaço escolar mais próximo do jovem e que realmente atinja suas necessidades. Isso significa que os jovens hoje anseiam por uma escola que atendam às suas necessidades e os ajude em suas experiências de vida (Soares, 2011).

$\mathrm{Na}$ busca de estudar e pesquisar novas propostas para diferenciar o processo educacional do estudante no Ensino Médio, foi organizada uma rádio escolar no colégio Alfa e foram organizadas produções de vídeos no colégio Beta. Tanto as produções da rádio como a elaboração de vídeos exigiram de professores e alunos o aprimoramento de habilidades e competências no uso de tecnologias variadas, tais como softwares de edição de vídeos. Além disso, houve outras contribuições pedagógicas relevantes como o desenvolvimento do senso de organização e do trabalho em equipe, além de uso desses meios comunicativos - rádio e vídeos - para a socialização de discussões no espaço educativo.

Por exemplo, no colégio Alfa, um dos resultados dessas habilidades, foi a inserção de discussões e debates, gerados a partir dos programas de rádio e dos vídeos, como instrumentos para atingir todo o público escolar. Os debates propostos eram temas julgados pelos alunos como importantes, tais como a sexualidade. $\mathrm{Na}$ ocasião, esse tema tinha sido discutido na aula de Biologia; foi um assunto que estava de fato latente entre os discentes. Assim, foi decidida pela a equipe da rádio escolar a discussão de sete minutos sobre esse assunto na programação da rádio, que tinha duração variável de dezesseis a dezenove minutos diário no intervalo de vinte minutos. Isso mostra um novo lugar no ambiente escolar, que pôde oferecer de fato oportunidade para que o aluno pudesse ter $\mathrm{VOz}$ atingindo seus anseios e necessidades.

A ideia dos projetos educomunicativos foi propor uma ação coletiva e democrática nas ações escolares, sendo uma questão de decisão ou escolhas dos alunos, e não da interferência da administração do colégio ou da gestão escolar que deveria ter por objetivo somente dar suporte e sequência para o desenvolvimento do projeto.

As tecnologias da informação e da comunicação foram aliadas na ação pedagógica, por isso é necessário e importante que os professores acompanhem as mudanças que naturalmente ocorrem, pois como destaca Perrenoud (2000), a formação para as várias tecnologias presentes na vida do aluno contribuirá para o desenvolvimento das várias habilidades como: criticidade, a criação de hipóteses, a leitura e interpretação dos vários tipos de linguagens e textos e a utilização dos inúmeros veículos para a comunicação nos dias atuais.

A necessidade dos alunos nativos digitais precisa ser atendida pelas instituições escolares para realmente absorver e atender o público que o compõe a cultura digital crescente e a cultura da mídia pois, conforme menciona Kellner (2001), a utilização dos meios de comunicação nos espaços educativos configura-se como essencial para fomentar as discussões sobre o ensino, promovendo um processo de reflexão nos projetos educativos, que tem como eixo a comunicação, promovido pelo agente provocador, que tem a função de filtrar e ponderar os assuntos escolhidos pelos alunos, e não de censurar. No caso, esse agente seria o professor/ mediador que foi a pessoa responsável por manter vivos os objetivos da ação comunicativa e motivação para continuação da existência do projeto no colégio privado, mas com sua essência pedagógica e não com ênfase em outros objetivos administrativos. 
O projeto escolar no colégio Alfa teve um funcionamento muito interessante voltado ao desenvolvimento pedagógico, porém, após um ano e meio de funcionamento, a administração do colégio interveio no objetivo do projeto tornando-o um projeto de "marketing" e com fins lucrativos. Desse modo, interferiu na essência da programação da rádio escolar, com propagandas sobre o colégio, tais como desconto e ação para a fidelização do irmão mais novo ou amigo, e outras ações com princípios para atingir o mercado. A rádio passou a ser um veículo de comunicação da administração do colégio, com outras vertentes, trazendo com menos ênfase os aspectos pedagógicos e sociais do projeto.

O mesmo processo ocorreu no Colégio Beta, pois os vídeos desenvolvidos pelos alunos foram conduzidos na sua produção pela administração do colégio. Por conseguinte, o projeto acabou por fortalecer outros interesses e não somente o desenvolvimento de habilidades e competências pedagógicas do seu público escolar.

Pensar nos ganhos em projetos escolares desenvolvidos pelos alunos e de cunho educomunicativos pela sua visibilidade nas redes sociais não é o problema e acredita-se que pode até ser importante, pois faz parte dos conjuntos oferecidos pelos colégios privados.

A experiência na implementação de Projetos Educomunicativos na rotina escolar dos Colégios Alfa e Beta mostrou que a tarefa foi árdua e que foi necessário tanto cuidar do aspecto pedagógico quanto administrativo, de investimento, para que houvesse um funcionamento adequado na rotina dos alunos durante os trabalhos. Durante a execução dos projetos, detectouse que a grande dificuldade não foi iniciar somente, pois foi necessário cuidar de várias etapas. Foi preciso a elaboração e a estruturação para o investimento; a venda da ideia para toda a equipe pedagógica e alunos; e, principalmente, foi fundamental manter o projeto vivo, funcionando e presente no cotidiano escolar com o seu objetivo central focado no desenvolvimento pedagógico, social e humano com uso de tecnologias da comunicação e informação.

Quando se inicia as ações de projetos, existem muitas expectativas, no que se referem aos cuidados pedagógicos, pois existe um programa de conteúdos anual para ser cumprido - seja em qualquer rede de ensino, municipal, estadual ou privada. O término do conteúdo programático é importante, segundo os currículos vigentes nas redes de ensino, as disciplinas precisam cumprir com os conteúdos proposto no ano letivo.

Para desenvolver de fato esses Projetos Educomunicativos, primeiramente foi necessário introduzir a cultura da ideia de desenvolver o ensino e aprendizagem a partir de desenvolvimento de projetos e introduzir isso no planejamento escolar anual. Em segundo, foi preciso propor uma discussão entre os professores o principal objetivo e vias de alimentação dos projetos com objetivos da melhoria do desenvolvimento das habilidades cognitivas dos alunos. No terceiro momento, com os projetos em andamento, cuidou-se do andamento da ação pedagógica por meio da manutenção das condições básicas para a continuação dos trabalhos, tais como, ter atenção aos equipamentos, produtos, marketing e outros.

Por último, para manter o funcionamento continuado do projeto e seus objetivos no ambiente escolar, observou-se ser indispensável a mobilização e a motivação de toda a equipe e dos alunos. Isso foi essencial para a compreensão da importância pedagógica do projeto escolar. Para isso, compreende-se que é essencial a formação contínua da equipe pedagógica envolvida.

Em relação aos Projetos Educomunicativos citados nesta pesquisa, foi possível destacar a liderança, o diálogo, ao protagonismo, atrelados e as interferências das ações nos resultados desses projetos. Desse modo, os benefícios trazidos, na aprendizagem, pelos projetos educomunicativos, são desvirtuados de sua proposta central de formação pedagógica e humana do indivíduo. É preciso, equilibrar as necessidades administrativas da instituição, com o desenvolvimento pedagógico dos alunos que fazem parte da mesma.

Assim, percebe-se que há vários desafios para manter o objetivo pedagógico de qualquer projeto embasado nas teorias da Educomunicação. Por exemplo, o investimento em equipamentos e formação das equipes para não se desviarem do real propósito da ação educomunicativas, pois têm grande importância e valor na execução desses projetos.

Há de se considerar a limitação de associar ao processo de fidelização da matrícula e do impacto midiático, junto aos pais e comunidade escolar, em que o projeto pode trazer. Não se pode desconsiderar a real importância da ação educativa: novas propostas de ensino para os jovens nativos digitais. Dessa forma, quando os professores gestores dos projetos têm de aceitar o condicionamento do projeto à administração do colégio, pode-se, em parte, reduzir o objetivo principal das ações educomunicativas de desenvolver o protagonismo do aluno, em função de outros propósitos.

Ambos os projetos, objetos desta pesquisa, por terem feito sucesso na comunidade escolar e também fora dela, encaminharam-se, em sua produção final, para a alimentação somente dos setores de "marketing" do colégio, tornando-se apenas um setor de propaganda da instituição. 
Os resultados propõem, portanto, a reflexão dos objetivos das ações e estratégias pedagógicas utilizando a tecnologia da informação e da comunicação para que possibilite efetivas contribuições benéficas no processo educacional. Nos casos apresentados nesta pesquisa, notou-se que o potencial obtido pelos projetos e a sua contribuição no plano pedagógico poderiam ser melhor explorados pela equipe gestora. Percebe-se, assim, que, nos colégios foco desta pesquisa, a meta e objetivo dos projetos mudam de rumos quando entram outros interesses que não valorizam a importância pedagógica da proposta no desenvolvimento dos discentes.

Entende-se que, para os colégios pesquisados, houve questões particulares que se desequilibraram dos projetos educacionais, trazendo certa inversão nos propósitos pedagógicos. Entretanto, os resultados da pesquisa podem incentivar um novo olhar para projetos de educomunicação, com propósitos claros de desenvolvimento dos estudantes e protagonismo juvenil. Além disso, espera-se incentivar outras unidades de ensino, públicas ou privadas para que possam desenvolver esses projetos com resultados positivos e incentivadores.

\section{Conclusão}

Nas condições atuais, a tecnologia é uma realidade que propõe vários benefícios sociais e, quando incorporada ao processo de ensino e aprendizagem, proporciona novas estratégias para o ensino e, principalmente, de aprendizado. A cultura e os valores da sociedade estão em transformações dinâmicas, exigindo novos acessos ao conhecimento e a formação de novos cidadãos mais críticos, criativos, competentes e dinâmicos.

As vantagens da inserção das tecnologias são benéficas em todas as áreas, inclusive na educação, área em que os recursos tecnológicos devem ser bem pensados, planejados, empregados e bastante utilizados, pois a educação, apesar de todo desenvolvimento que passamos, continua sendo a base para a formação dos cidadãos, preparando-os para a vida e para a sociedade contemporânea. Entretanto, é necessário saber usufruir desses recursos, fazendo com que eles contribuam para a melhoria da qualidade do processo de ensino e aprendizagem. Com tudo, a pesquisa-ação contribuiu com a ideologia proposta pela ação pedagógica na transformação das práxis sociais e na formação do sujeito como ser transformador no processo de aprendizagem e na sociedade.

É necessário aliar as tecnologias às novas metodologias, como Projetos Educomunicativos, tornando esse processo eficaz, fazendo com que a bagagem do mundo real que os alunos já trazem para a escola seja transformada em conhecimento mais dinâmico e funcional para o mundo fora dos tradicionais muros escolares. É nesse momento que o professor deixa de lado seu status quo como detentor do conhecimento e passa a ser o mediador, de modo que os alunos também se sintam sujeitos ativos e protagonistas deste processo, ou seja, explorem as informações, socializem o saber e construam seu conhecimento.

\section{Referências}

Alcici, S.A.R. 2014. Escola na sociedade moderna. In: Almeida, N. A. (Coord.) et al. Tecnologia na escola: abordagem pedagógica e abordagem técnica. Cengage Learning, São Paulo, SP, Brasil.

Franco, M.A.S. 2005. Pedagogia da Pesquisa-Ação. Educação e Pesquisa 31: 483-502.

Gil, A.C. 2010.Como elaborar projetos de pesquisas. 4ed. Atlas, São Paulo, SP, Brasil.

Kellner, D. 2001. A Cultura da mídia. EDUSP, Bauru, SP, Brasil.

McLuhan, M. 2002. Os meios de comunicação como extensões do homem. (Understanding media). Trad. Décio Pignatari.12 ed. Cultrix, São Paulo, SP, Brasil.

Moran, J.M. 2000. Novas tecnologias e mediação pedagógica. Papirus, Campinas, SP, Brasil.

Moreira, H.; Calefe, L. G.2008. Metodologia da pesquisa para o professor pesquisador. 2 ed. Lamparina, Rio de Janeiro, RJ, Brasil.

Perrenoud, P. 2000. Dez novas competências para ensinar. Artes Médicas, Porto Alegre, RS, Brasil.

Soares, I.O. 2011.Educomunicação: o conceito, o profissional, a aplicação: contribuições para a reforma do Ensino Médio. Paulinas, São Paulo, SP, Brasil.

Toschi, M.S. 2005.Tecnologia e educação: contribuições para o ensino. Serie Estudos 19: 35-42. 